Vol. 16, $n^{\circ} 2$ | 2012

Varia

\title{
Marco Cavina, Le nozze di sangue. Storia della violenza coniugale
}

Roma, Bari, Laterza, 2011, 249 p. ISBN 978-88-420-9541-5.

\section{Marco Cicchini}

\section{OpenEdition}

\section{Journals}

Édition électronique

URL : http://journals.openedition.org/chs/1368

DOI : $10.4000 /$ chs. 1368

ISSN : 1663-4837

\section{Éditeur}

Librairie Droz

Édition imprimée

Date de publication : 1 décembre 2012

Pagination : 111-113

ISBN : 978-2-600-01642-1

ISSN : $1422-0857$

\section{Référence électronique}

Marco Cicchini, « Marco Cavina, Le nozze di sangue. Storia della violenza coniugale », Crime, Histoire \&

Sociétés / Crime, History \& Societies [En ligne], Vol. 16, n² | 2012, mis en ligne le 13 mars 2013,

consulté le 22 septembre 2020. URL : http://journals.openedition.org/chs/1368 ; DOI : https://doi.org/ 10.4000/chs. 1368

Ce document a été généré automatiquement le 22 septembre 2020

(c) Droz 


\title{
Marco Cavina, Le nozze di sangue. Storia della violenza coniugale
}

Roma, Bari, Laterza, 2011, 249 p. ISBN 978-88-420-9541-5.

\author{
Marco Cicchini
}

\section{RÉFÉRENCE}

Marco Cavina, Le nozze di sangue. Storia della violenza coniugale, Roma, Bari, Laterza, 2011, 249 p. ISBN 978-88-420-9541-5.

1 En Italie, fin mars de l'année 2012, la statistique judiciaire établit ce chiffre troublant: tous les deux jours, une femme succombe aux sévices que lui inflige son conjoint. Ainsi placée sous les feux de la rampe, la violence domestique a-t-elle pour autant jamais quitté le théâtre des drames sociaux? Professeur d'histoire du droit médiéval et moderne à l'Université de Bologne et auteur de plusieurs monographies sur l'histoire de la justice criminelle (notamment Il duello giudiziario per punto d'onore, 2003), Marco Cavina entend contribuer à une réflexion dépassionnée sur un sujet d'une imperturbable actualité en proposant une approche diachronique de large spectre. Disons-le d'emblée : consacrer à peine 200 pages à la «violence conjugale » (celle des époux sur les épouses) sur une période aussi vaste (du Moyen Âge à nos jours) relève de la gageure. Monographies historiennes récentes, doctrine juridique et patristique, littérature classique et moraliste: copieusement documentée, la synthèse qui en ressort,d'une singulière clarté, donne à penser.

2 Le problème que soulève Cavina peut se résumer ainsi. Comment et jusqu'à quel point la conception patriarcale de la société, en ses linéaments culturels et anthropologiques les plus divers, a-t-elle façonné la morphologie des relations conjugales en Occident, au point de justifier, moralement, juridiquement, la violence des hommes sur les femmes dans le cadre du mariage ? Car, avant de devenir «violence conjugale » à proprement parler, les corrections infligées par les maris dans le cadre du mariage ont été un droit reconnu et légitimé. Pour son enquête, l'auteur n'hésite pas à remonter aux origines du 
mariage chrétien et à rappeler les fondements du « devoir conjugal », conçu à la lettre du texte de Paul de Tarse comme un devoir réciproque, mais interprété dans la perspective hiérarchisée et sexuée des rôles comme une dette de l'épouse envers son époux. L'approche chrétienne du mariage est fondée sur la subordination de la femme à l'autorité du mari, bien que celui-ci ne doive exercer sa puissance maritale qu'avec modération et droiture. Dès lors, à partir du Moyen Âge, moralistes et juristes s'attèlent à définir un cadre légitime au pouvoir correctionnel du paterfamilias. On trouve trace de cette entreprise limitative parmi les théologiens, ainsi que dans les statuts des communautés urbaines ou régionales médiévales. En Europe, si la dénonciation radicale de la violence maritale par un William Heale (1581/2-1628) est une voix isolée, le pouvoir correctionnel des maris est légitimé dès lors qu'il est « contenu dans de justes bornes ». Au XVI ${ }^{e}$ siècle, le juriste André Tiraqueau prône la modération dans l'exercice du droit de correction, mais non sa suppression, de même que le Livre du courtisan (1528) de Baldassar Castiglione fait de la retenue dans la relation conjugale une exigence de civilité.

3 Pour Cavina, les violences domestiques, au bas Moyen Âge et durant l'époque moderne, découlent en grande partie de la dimension charnelle du lien matrimonial: l'actualisation du mariage repose sur le don du corps auquel consentent les époux. Viol et «crime d'honneur» sont alors des formes de brutalité conjugale qui expriment la consommation nécessaire du mariage au sein d'une union exclusive, dominée par la figure masculine. Bien que l'homicidede la femme adultère s'inscrive dans un ordre familialiste de la société, une telle action est considérée par les théologiens comme un péché mortel, alors qu'aux yeux des juristes, l'uxoricide, en pareil cas, peut bénéficier de circonstances atténuantes. L'affirmation de l'État de justice, dès le XIV ${ }^{e}$ siècle en Italie, constitue en fait le frein principal à la vengeance des maris ou de leurs parents. L'extension des prérogatives des tribunaux dans le domaine familial, par exemple, permet aux femmes de faire valoir les sévices comme juste cause à la séparation de corps, terrain sur lequel s'engagent les Décrétales de Grégoire IX dès 1234. Au cours de l'époque moderne, un catalogue de mauvais traitements infligés aux femmes est progressivement dressé par les juristes au point d'étendre les droits des épouses tout en limitant ceux des maris.

4 À la veille de la Révolution française, l'idée de correction maritale a grandement perdu de son sens et est considérée par les élites comme une pratique dégradante prévalant au sein des couches sociales les plus basses. À Rome, dans les années 1770, Cristoforo Cosci appuie la cause des femmes violentées par un traité dont l'influence déteint sur la pratique des tribunaux. Contre la tyrannie des pères et des maris qui abusent de leur autorité paternelle ou maritale, Carolina Lattanzi (1771-1818) fait paraitre en 1797 son brûlot «féministe " sur la Schiavitù delle donne (L'esclavage des femmes). Mais comme le montrent les travaux récents sur les politiques familiales à l'âge des révolutions, les révolutionnaires français sont loin de remplacer la famille patriarcale par la famille individualiste et libérale. Le code civil napoléonien, qui réaffirme le devoir d'obéissance de l'épouse, en est l'illustration la plus manifeste. C'est pourtant bien au XIX siècle que le droit de correction du mari devient caduc. Les sévices domestiques ne constituent plus seulement une cause légitime de séparation, mais aussi et surtout un crime, répréhensible en tant que tel par la justice pénale. L'évolution contemporaine des relations conjugales est traitée plus rapidement par l'auteur qui rappelle les grandes étapes juridiques qui permettent, du moins en droit, une plus grande protection des femmes. Ainsi, depuis 1978 en Italie, la contrainte sexuelle exercée sur les épouses n'est 
plus considérée au nombre des droits des maris. De même, les circonstances atténuantes du "crime d'honneur ", dont bénéficient quasi automatiquement les maris trompés jusqu'au début $\mathrm{du} \mathrm{XX}^{\mathrm{e}}$ siècle, sont reçues pour la dernière fois par les tribunaux italiens en 1981.

5 De ce parcours à grandes enjambées par-dessus les siècles, Cavina garde le cap pour montrer le mouvement d'affirmation puis de déconstruction de la conception patriarcale du mariage, et l'incidence du cadre moral et juridique sur la manière de saisir les «violences conjugales ». Entière demeure pourtant l'énigme de la criminalité conjugale contemporaine : faut-il y voir, comme le suggère Cavina, les vestiges d'un substrat patriarcal toujours fertile, malgré les condamnations juridiques dont il fait l'objet en Occident? Un substrat culturel et mental que la littérature vient pourtant, depuis la Renaissance (Chaucer ou Boccaccio par exemple), remettre régulièrement en question. Si le tableau final qui ressort de ce livre est tout en nuances - la violence conjugale extrême n'a jamais été, sauf en de rares exceptions, purement et simplement absoute -, manque cependant une analyse plus substantielle de la pratique judiciaire ou pénal de la problématique. Reste, et c'est sans doute là l'essentiel pour un ouvrage de synthèse, que Cavina stimule de belles et nombreuses interrogations sur la criminalité conjugale comme objet d'histoire.

\section{AUTEURS}

\section{MARCO CICCHINI}

Université de Genève

marco.cicchini@unige.ch 